\title{
Internet of Things (IOT) Development for The Chicken Coop Temperature and Humidity Monitoring System Based On Fuzzy
}

\author{
${ }^{1}$ Jamaluddin Husein, ${ }^{2}$ Oktaf Brillian Kharisma \\ ${ }^{1,2}$ Departement of Electrical Engineering,State Islamic University of Sultan Syarif Kasim Riau \\ Email: 1jamaluddin.husein@students.uin-suska.ac.id, ${ }^{2}$ brilliankhar@gmail.com
}

\begin{tabular}{|c|c|}
\hline Article info & ABSTRACT \\
\hline Article history : & The high increase in broiler each year there are several factors that must \\
\hline Received February $02^{\text {th }}, 2020$ & be considered, one of them is the temperature and humidity of the cage. \\
\hline Revised February $20^{\text {th }}, 2020$ & The brooding cage space of ten chickens $/ 1 \mathrm{~m}^{2}$. If more then that couse \\
\hline Accepted March $14^{\text {th }} 2020$ & $\begin{array}{l}\text { broiler is not optimal. The temperatur needed is } 29^{\circ} \mathrm{C}-35^{\circ} \mathrm{C} \text { and } \\
\text { humidity } 60 \%-70 \% \text { for brooding. In general control of temperature and } \\
\text { humidity, unable to maintain cage needs. Then it is necessary to do } \\
\text { automatic control using the fuzzy logic method and the concent of }\end{array}$ \\
\hline Keyword: & Internet of Things (IoT). Base on the testing result the system has been \\
\hline Temperature & able to maintain the set point of temperature and humidity and get \\
\hline Humidity & broiler growth not same. The best stability value during the test is \\
\hline Broiler & condition without DOC produces no overshoot temperature parameters \\
\hline Brooding & and steady state error 0.48 , no overshoot and steady state for humidity. \\
\hline Fuzzy & On the condition with DOC produces overshoot temperature 0.06 and \\
\hline Things (IoT) & $\begin{array}{l}\text { steady state error } 0.15 \text {, and overshoot } 0.1 \text { and steady state } 0.4 \text { for } \\
\text { humidity. While on the IoT concept has been able to display the } \\
\text { temperature and humidity values on the cage. }\end{array}$ \\
\hline
\end{tabular}

Copyright (C2020 Puzzle Research Data Technolog y

\author{
Corresponding Author : \\ Jamaluddin Husein \\ Department of Electrical Engineering \\ Faculty of Science and Technology \\ State Islamic University of Sultan Syarif Kasim Riau \\ Soebrantas 155 Pekanbaru - Indonesia \\ Email: jamaluddin.husein@students.uin-suska.ac.id
}

DOI : http://dx.doi.org/10.24014/ijaidm.v3i1.9294

\section{PENDAHULUAN}

Kebutuhan unggas di Indonesia saat ini meningkat seiring bertambahnya jumlah penduduk, hal tersebut akan menjadi masalah jika tidak diimbangi dengan meningkatkan populasi unggas yang dihasilkan. Salah satu jenis unggas adalah ayam ras pedaging (Broiler). Broiler adalah unggas hasil rekayasa genetika yang memiliki karakteristik pertumbuhan cepat per satuan waktu, serta menghasilkan daging berkualitas dengan serat yang lunak. Menurut kecepatan pertumbuhannya, maka periode pemeliharaan broiler dapat dibagi menjadi dua yaitu periode starter dan finisher[1][2].

Pada masa pemeliharaan day old chick (DOC), umumnya menggunakan jenis kandang panggung terbuka, yang memiliki ketinggian alas kandang dari tanah sekitar 1-2 m. Pemilihan kandang panggung terbuka adalah proses pembuatan kandang yang relatif lebih murah dari pada pembuatan kandang tertutup dan juga memiliki sirkulasi udara lancar dan hemat dalam penggunaan listrik [1].

Berdasarkan peraturan menteri pertanian Republik Indonesia No.31 tahun 2014 tentang pedoman budi daya ayam pedaging dan ayam petelur yang baik, bahwa kepadatan kandang yang ideal untuk daerah tropis, seperti indonesia adalah $100-500$ ekor $/ 50 \mathrm{~m}^{2}$ atau $10 \mathrm{ekor} / 1 \mathrm{~m}^{2}$. Jika lebih dari angka tersebut, maka suhu kandang akan cepat meningkat. Akibatnya bisa menyebabkan konsumsi pakan menurun, ayam cenderung banyak minum, stres, pertumbuhan terhambat, dan mudah terserang penyakit. Kebutuhan suhu dan kelembapan yang dibutuhkan broiler pada masa brooding $29^{\circ} \mathrm{C}-35^{\circ} \mathrm{C}$ dan kelembapannya $60 \%-70 \%$, sedangkan masa setelah brooding selesai suhu yang dibutuhkan $24^{\circ} \mathrm{C}-29^{\circ} \mathrm{C}$ dan kelembapan $60 \%-70 \%$. Masa 
brooding adalah ketika DOC berumur 1-14 hari, sedangkan masa setelah brooding adalah broiler berumur 14-27 hari [3][4].

Proses pengaturan suhu dan kelembapan yang konstan dapat disesuaikan dengan menggunakan sistem brooder thermos. Sistem brooder thermos terdapat tirai di dalam dan di luar kandang. Metode konvensional ini masih digunakan oleh peternak untuk mengatur suhu dan kelembapan pada kandang. Metode konvensional tersebut dilakukan dengan membuat lingkaran-lingkaran dari bahan seng, kemudian dilengkapi satu buah brooder sebagai pengatur suhu dan kelembapan kandang. Pengaturan suhu dan kelembapan kandang dengan metode konvensional, perlu dilakukan pengawasan karena dua parameter tersebut mudah sekali mengalami perubahan [1] [4].

Perubahan dari nilai suhu dan kelembapan yang sangat cepat berubah-ubah menjadi faktor tidak tercapainya nilai set point. Berdasarkan permasalahan tersebut maka penelitian ini akan melakukan pengendalian suhu dan kelembapan secara otomatis dengan menggunakan kendali fuzzy dan pemantauan terkini dengan memanfaatkan konsep Internet of Things (IoT) [5][6].

Kasus yang pernah terjadi akibat kurangnya perhatian terhadap suhu dan kelembapan adalah tidak meratanya pertumbuhan bobot badan pada ayam yang dihasilkan hingga masa panen. Masa panen yang dilakukan pada broiler umur 35 hari dengan jumlah 60 ekor broiler, suhu rata-rata adalah $29,88^{\circ} \mathrm{C}$, bobot ayam rata-rata 692,56 g yaitu bobot terkecil $397 \mathrm{~g}$ dan terbesar $1126 \mathrm{~g}$ [5].

Beberapa penelitian terkait tentang pengendalian suhu dan kelembapan pada kandang ayam yang dilakukan dengan menggunakan gsm shield untuk mengirimkan pesan singkat kondisi suhu dan kelembapan pada kandang dan ditampilkan pada lcd 16x2. Pengendalian suhu dan kelembapan digunakan menggunakan kipas dan lampu. Kelemahan dari sistem ini adalah belum adanya pengaturan suhu dan kelembapan pada masa brooding, maka perlu dilakukan pengendalian suhu dan kelembapan untuk mencapai parameter yang dibutuhkan [3].

Pada penelitian lainnya terkait pengendalian suhu dan kelembapan pada kandang ayam, selain nilai suhu dan kelembapan yang dilakukan pengendalian juga terdapat modul RTC DS1307 yang berfungsi untuk menentukan hari sebagai acuan umur ayam sehingga suhu acuan dapat sesuai. Namun kelembapan yang dihasilkan masih belum maksimal, yaitu sebesar 50\%-70\%, dan ketika kelembapan diatas 70\%, sistem belum bisa menurunkan kelembapan kandang, tanpa mempengaruhi nilai suhu kandang [6].

Selain itu pengendalian suhu dan kelembapan pada kandang ayam dengan pemberian pakan otomatis, pengendalikan lampu, blower, dan mist maker berdasarkan pembacaan sensor DHT11. LCD 16x2 dapat menampilkan nilai bacaan dari sistem. Kelemahan sistem ini adalah monitoring suhu dan kelembapan hanya dapat dilakukan jika berada di dekat kandang dengan memperhatikan nilai yang ada pada LCD [8].

Kemudian Perkembangan penelitian pengaturan suhu dan kelembapan kandang ayam selanjutnya dengan menggunakan sistem kendali. Pengendalian suhu dan kelembapan dikendalikan dengan menggunakan metode logika fuzzy pada masa brooding, sedangkan pada masa setelah brooding digunakan cara konvensional. Sistem yang dirancang juga mampu untuk memberikan pakan secara otomatis dan membersihkan kotoran ternak di dalam kandang. Hasilnya sistem dapat bekerja dengan baik, hal ini ditentukan dengan tercapainya set point nilai suhu dan kelembapan dalam ruangan sesuai dengan yang diinginkan. Sistem ini belum ada pemantauan informasi terkini berdasarkan nilai suhu dan kelembapan pada kandang [8].

Pemilihan Kendali logika Fuzzy mampu mengenali variabilitas dan linguistik dalam proses brooder, misal suhu udara. Fuzzy mampu memprediksi waktu proses yang diperlukan dan prediksi ketika penyesuaian proses perlu dilakukan dilakukan, ini menghilangkan kebutuhan operator[3]. Selain itu, logika fuzzy lebih mudah dimodifikasi karena lebih mudah dimengerti dan dimodifikasi aturan-aturannya[3][8].

Pengembangan IoT yang digunakan dapat melakukan monitoring suhu dan kelembapan pada kandang ayam. Sistem pengaturan suhu dan kelembapan pada kandang ayam dapat dikendalikan secara otomatis dengan menggunakan metode logika fuzzy. Pengaturan suhu dan kelembapan dikendalikan berdasarkan pengaturan lampu dan kipas, sehingga menghasilkan pertambahan bobot badan yang seragam pada broiler, dengan keadaan sehat. Perangkat pendukung yang digunakan yaitu dengan cara memasangkan sensor DS18B20 untuk mengukur suhu dan sensor DHT22 untuk mengukur kelembapan udara. Arduino uno digunakan sebagai mikrokontroler dan ESP8266 sebagai modul WiFi yang digunakan agar sistem dapat terhubung ke website, LCD (Liquid Cristal Display) 16x2 digunakan sebagai display informasi nilai suhu dan kelembapan yang dipasang pada kandang.

\section{METODOLOGI PENELITIAN}

Metode yang digunakan dalam penelitian ini adalah deskriptif kualitatif. Jenis penelitian deskriptif kualitatif merupakan sebuah metode penelitian yang memanfaatkan data kualitatif dan dijabarkan secara deskriptif. Jenis penelitian deskriptif kualitatif menampilkan hasil data apa adanya tanpa proses manipulasi atau perlakuan lain.

IJAIDM Vol. 3, No. 1, March 2020: $9-20$ 
Adapun tahap dalam penelitian ini adalah melakukan studi pra riset dengan melakukan observasi ke beberapa peternakan rakyat yang ada di sekitaran kampus UIN Suska Riau, untuk mengetahui data-data yang berkaitan dengan jenis kandang, ukuran, jumlah DOC, suhu dan kelembapan pada kandang ayam broiler. Kemudian melakukan studi literatur yang berkaitan dengan kandang yang akan dibuat untuk proses brooding pada DOC. Kandang yang digunakan adalah kandang jenis panggung terbuka yang pada kategori kandang open house dengan ukuran $100 \mathrm{~cm}$ x $50 \mathrm{~cm}$ x $75 \mathrm{~cm}$. Untuk jumlah broiler (DOC) pada masa brooding di isi dengan jumlah 10 ekor.

Tahap selanjutnya menentukan komponen yang akan digunakan kemudian menggambarkan blok diagram keseluruhan sistem. Tahapan yang terakhir yaitu menjelaskan keterkaitan komponen satu dengan yang lainnya sehingga menjadi satu kesatuan sistem yang sempurna. Agar menghasilkan pengukuran kandang yang akurat, pengukuran suhu diukur dengan menggunakan 3 buah sensor suhu yang diletakkan pada posisi kanan, tengah dan kiri di dalam kandang dengan jarak $10 \mathrm{~cm}$ dari lantai (litter). Tujuannya agar menghasilkan suhu rata-rata yang homogen yang dapat dirasakan oleh DOC di dalam kandang. Untuk sensor kelembapan digunakan cukup satu sensor saja di bagian tengah, sebab uap yang dihasilkan bersifat menyebar ke seluruh ruang. Agar pemanas memiliki karakteristik cepat menghasilkan panas dengan waktu yang singkat, maka digunakan lampu pijar sebagai pemanas yang berkapasitas 60 watt dan sebuah kipas DC $12 \mathrm{~V}$ untuk menyebarkan hawa panas ke seluruh ruang di dalam kandang. Berikut ini gambar perancangan tata letak sensor:

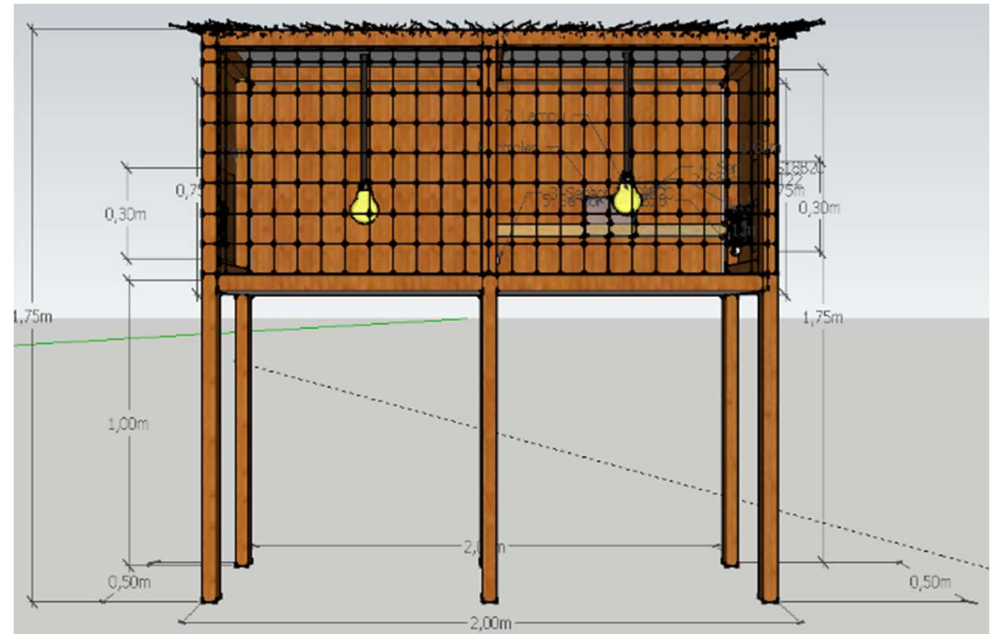

Gambar 1. Model Tata Letak Komponen

Keterangan gambar model perancangan :

1. Kontroler

2. Sensor DHT22

3. Sensor DS18B20 (Bagian samping Kiri)

4. Sensor DS18B20 (Bagian Tengah)

5. Sensor DS18B20 (Bagian Kanan)

6. Kipas

7. Lampu

\subsection{Diagram Perancangan Sistem}

Perancangan sistem pengaturan suhu dan kelembapan pada kandang ayam ini terdiri dari perangkat keras yang aktifitasnya dikendalikan oleh perangkat lunak sehingga semua sistem dapat saling berhubungan. Sistem yang dirancang dapat bekerja secara otomatis bila mendapatkan masukan dari luar. Secara blok diagram dapat dibagi menjadi beberapa bagian yang dapat dilihat pada gambar 2 .

Blok diagram perancangan sistem dibuat berdasarkan cara kerja rangkaian secara keseluruhan. Blok diagram di atas dapat diketahui bahwa konfigurasi sistem pengaturan suhu dan kelembapan ini terdiri dari input, proses dan output. Input yang terdiri dari sensor DHT22, DS18B20, dan RTC DS3231. Kontroler (proses) yang digunakan adalah arduino uno, dan ESP8266. Output yang digunakan adalah rangkaian AC Dimmer yang akan mengendalikan pemanas, driver L298N mengendalikan kecepatan putaran kipas sesuai dengan nilai set point, LCD 16x2 dan website untuk menampilkan nilai suhu dan kelembapan. 


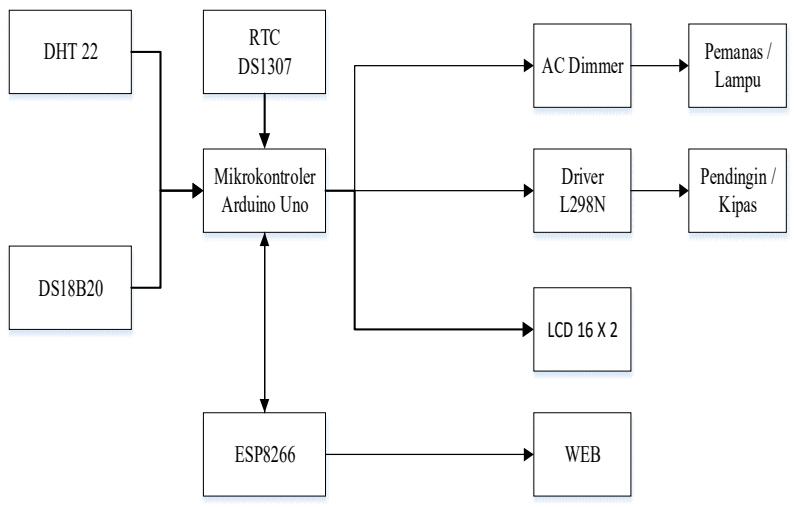

Gambar 2. Blok Diagram Perancangan Sistem

\subsection{Diagram Perancangan Hardware Keseluruhan}

Alat pengaturan suhu dan kelembapan pada kandang ayam ini bekerja berdasarkan pengaturan suhu dan kelembapan. Ketika suhu di bawah set point maka digunakan pemanas untuk menaikkan suhu. Sensor yang digunakan untuk mendeteksi suhu adalah DS18B20, sedangkan untuk mendeteksi kelembapan digunakan sensor DHT22. Pada saat sistem $O N$ pemanas akan akif dan mengakibatkan suhu akan naik. Jika sensor DS18B20 mendeteksi bahwa suhu di atas set point lampu akan aktif untuk mempertahankan nilai set point suhu pada kandang. Penerapan dengan menggunakan logika fuzzy, kecepatan kipas dan pengaturan pemanas dapat di sesuaikan berdasarkan nilai suhu dan kelembapan yang terbaca pada sensor.

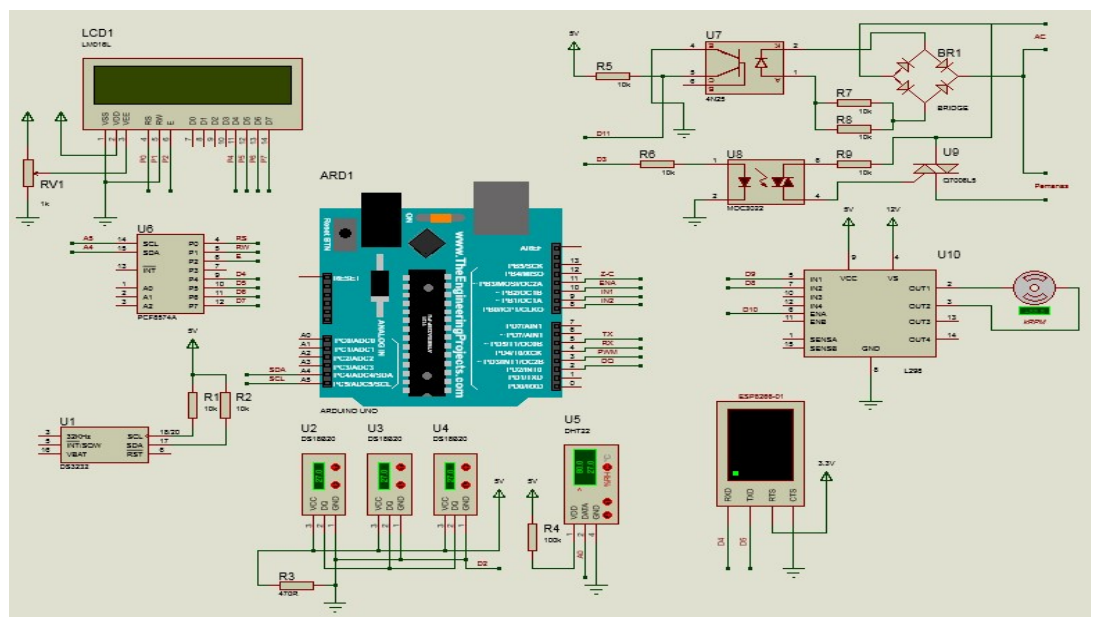

Gambar 3. Rangkaian Hardware Keseluruhan

\subsection{Perancangan Logika Fuzzy pada Suhu}

Logika fuzzy mengolah informasi dari variabel numerik menjadi variabel linguistik. Pengendali logika fuzzy dirancang untuk mengatur besarnya variabel tegangan output dengan masukan berupa variabel error dan variabel delta error Variabel error didefenisikan sebagai selisih antara nilai suhu terukur dikurangi dengan nilai set point, sedangkan variabel derror didefenisikan sebagai selisih nilai error sekarang dikurangi dengan nilai error sebelumnya.

$$
\begin{aligned}
& \text { Error }=\text { Suhu setpoint }- \text { Suhu terukur } \\
& \text { D-error }=\mid \text { Error }_{n}|-| \text { Error }_{n-1} \mid
\end{aligned}
$$

Untuk mendapatkan nilai Error dan D-error, maka dilakukan pengukuran pada pembacan sensor pada sistem, setelah data-data didapatkan tahapan selanjutnya adalah melakukan tahapan fuzzifikasi, pembentukan rules, inferensi dan tahapan defuzzifikasi.

Pada pengendalian suhu set point yaitu $32^{\circ} \mathrm{C}$ dangan batas bawah $29^{\circ} \mathrm{C}$ dan batas atas $35^{\circ} \mathrm{C}$, untuk menentukan nilai range error didapatkan dengan mengurangkan nilai batas bawah dan nilai batas atas 
dengan set point suhu sehingga didapatkan hasil untuk Error batas bawah -3 dan batas atas 3 . Pemilihan range Error suhu -3 sampai 3 adalah untuk menjaga set point suhu tidak keluar dari batas yang ditentukan, dikarenakan Suhu pada masa brooding adalah $29^{\circ} \mathrm{C}-35^{\circ} \mathrm{C}$. Pada variabel Error suhu, data yang dimiliki adalah -2, -1, 0, 1, dan 2. Maka pada variabel ini dibagi menjadi 3 himpunan Fuzzy, yaitu EN (Error Negatif), EZ (Nol) dan EP (Error Positif). Himpunan Fuzzy EN akan memiliki domain [-2, 0], EZ memiliki domain [1, 1] dan EP memiliki domain [0, 2]. Input crisp Error suhu dapat dilihat pada gambar 4.

Sedangkan Nilai keanggotaan variabel Derror didapatkan berdasarkan respon sensor suhu DS18b20 terhadap perubahan suhu pada sistem. Sesuai dengan hasil pengamatan dengan menggunakan alat ukur hygrometer maka nilai veriabel Derror yaitu -3 sampai dengan 3.
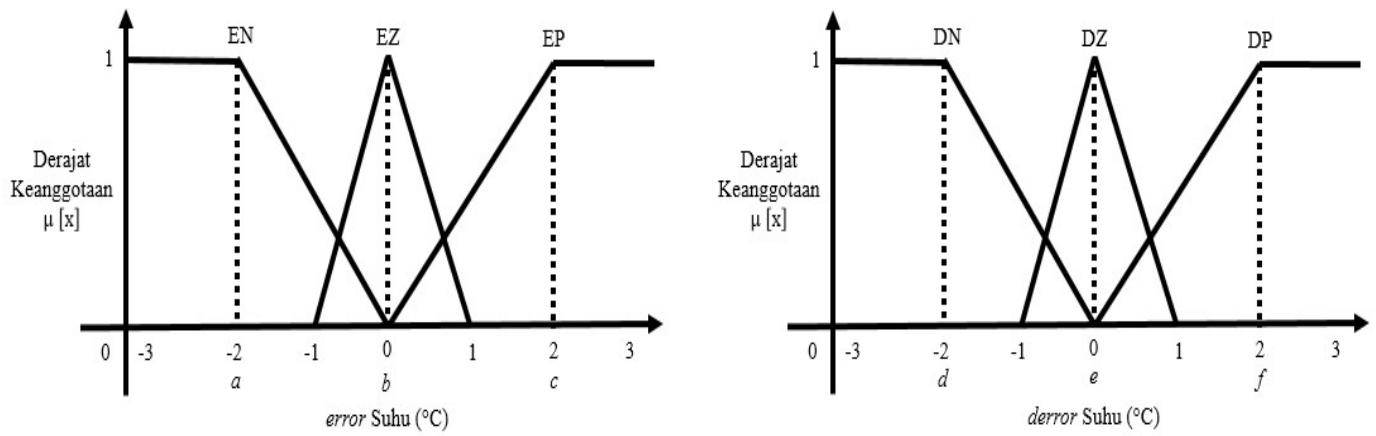

Gambar 4. Membership Function Error dan Deror Suhu

Pada variabel Derror suhu, data yang dimiliki adalah -2, -1, 0, 1, dan 2. Maka pada variabel ini dibagi menjadi 3 himpunan Fuzzy, yaitu DN (Derror Negatif), DZ (Derror zerol) dan DP (Derror Positif). Himpunan Fuzzy EN akan memiliki domain [-2, 0], EZ memiliki domain [-1, 1] dan EP memiliki domain [0, 2]. Berikut ini tabel pengamatan suhu yang dilakukan dengan menggunakan alat ukur hygrometer.

Tabel 1. Pengamatan Suhu Dengan Hygrometer

\begin{tabular}{ccccc}
\hline Waktu uji (WIB) & 06.00 & 12.00 & 17.00 & 20.00 \\
\hline Temperatur $\left({ }^{\circ} \mathrm{C}\right)$ & 24 & 27 & 29 & 26 \\
\hline Error & 8 & 5 & 3 & 6 \\
\hline Derror & & -3 & 2 & -3 \\
\hline
\end{tabular}

Variabel output pada kendali suhu adalah PWM yang berfungsi untuk mengendalikan rangkaian AC Dimmer. Rangkaian AC Dimmer berfungsi untuk mengatur tegangan yang masuk pada pemanas (lampu), dengan mengendalikan intensistas cahaya. Variabel output ini dibagi menjadi 3 himpunan Fuzzy yaitu, Panas dengan domain [30], Hangat dengan domain [60], dan Dingin dengan domain [90].

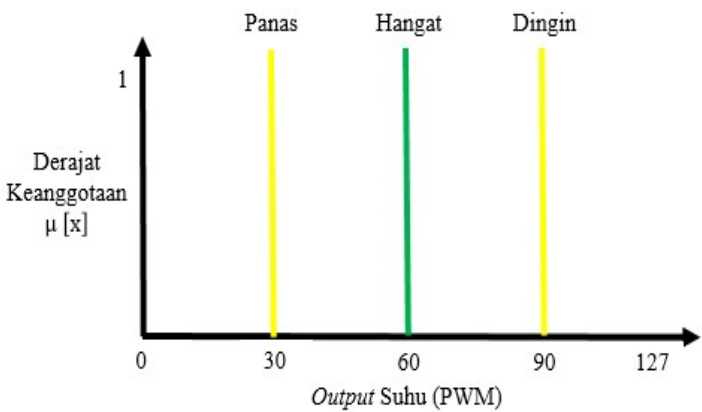

Gambar 5. Output Membership Function Suhu

Secara umum respon fungsi step suatu sistem kendali memberikan output. Pada saat sistem diaktifkan, output akan bekerja dengan cepat menuju set point yang diatur pada suhu. Pengaturan output diturunkan atau dinaikkan sesuai dengan error dan derror hingga output mencapai set poin. Sehingga kontroler dapat mengambil tindakan yang tepat untuk menyesuaikan output-nya.

Metode inferensi yang digunakan adalah Tsukamoto. Pada Metode Tsukamoto, setiap konsekuen pada aturan yang berbentuk IF-Then harus dipresentasikan dengan suatu himpunan fuzzy dengan fungsi 
keanggotaan yang monoton. Sebagai hasilnya, output hasil inferensi dari tiap-tiap aturan diberikan secara tegas (crisp) berdasarkan a-predikat (free strength). Berikut ini merupakan rule suhu yang akan buat.

Tabel 2. Rules Base Kendali Logika Fuzzy Suhu

\begin{tabular}{cccc} 
& & & \\
& & EN & \\
\hline $\mathrm{DN}$ & Panas & Dingin & Dingin \\
$\mathrm{DZ}$ & Panas & Hangat & Dingin \\
$\mathrm{DP}$ & Panas & Panas & Dingin \\
\hline
\end{tabular}

\subsection{Perancangan Logika Fuzzy pada Kelembapan}

Pada pengendalian kelembapan set point yaitu 65\% dangan batas bawah $60 \%$ dan batas atas $70 \%$, untuk menentukan nilai range error didapatkan dengan mengurangkan nilai batas bawah dan nilai batas atas dengan set point suhu sehingga didapatkan hasil untuk Error batas bawah -3 dan batas atas 3 .

Pada variabel Error kelembapan, data yang dimiliki adalah -2 (h), 0 (i), dan 2 (j), dengan demikian pada variabel ini dibagi menjadi 3 himpunan Fuzzy, yaitu EK (Error Kecil), ES (Nol) dan EB (Error Besar). Himpunan Fuzzy EK akan memiliki domain [-2,0], ES memiliki domaian [-1, 1] dan EB memiliki domain $[0,2]$. Input crisp Error kelembapan dapat dilihat pada gambar 6.
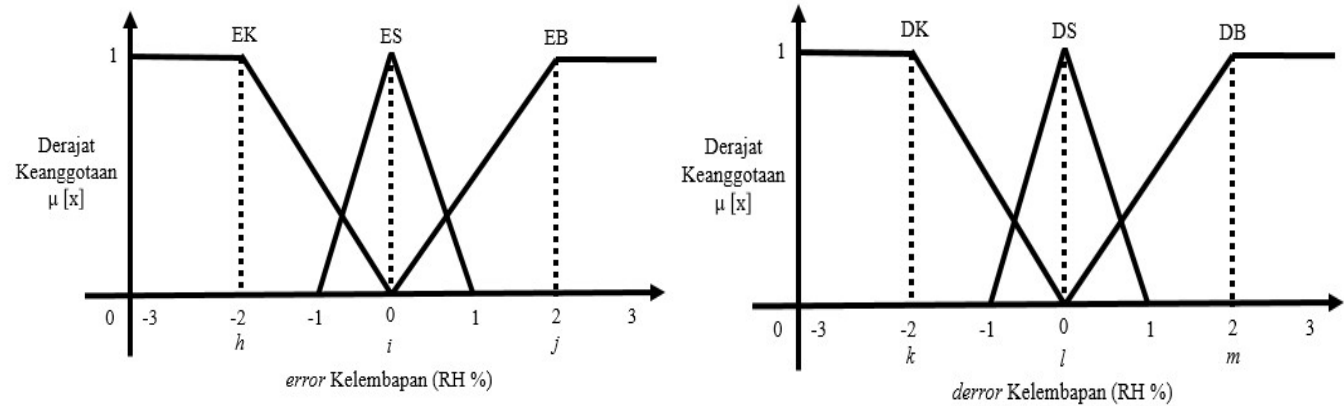

Gambar 6. Membership Function Error dan Derror Kelembapan

Nilai keanggotaan variabel derror didapatkan berdasarkan respon sensor kelembapan DHT22 terhadap perubahan kelembapan pada sistem. Sesuai dengan hasil pengamatan dengan menggunakan alat ukur hygrometer maka nilai veriabel Derror yaitu -3 sampai dengan 3. Sedangkan pada variabel Derror kelembapan, data yang dimiliki adalah $-2,-1,0,1$, dan 2 . Maka pada variabel ini dibagi menjadi 3 himpunan Fuzzy, yaitu DK (Kurang lembab), DS (Pas) dan DB (Sangat lembab). Himpunan Fuzzy DK akan memiliki domain $[-2,0]$, DS memiliki domain $[-1,1]$ dan DK memiliki domain $[0,2]$. Berikut ini tabel pengamatan kelembapan dengan menggunakan alat ukur hygrometer.

Variabel output pada kendali kelembapan adalah PWM yang berfungsi untuk mengendalikan driver L298N. Driver L298N berfungsi untuk mengatur tegangan yang masuk pada pendingin (kipas), dengan mengendalikan kecepatan motor DC. Variabel output ini dibagi menjadi 4 himpunan Fuzzy yaitu, SL (Sangat Lambat) dengan domain [0], L (Lambat) dengan domain [100], S (Sedang) dengan domain [175], dan K (Kencang) dengan domain [225].

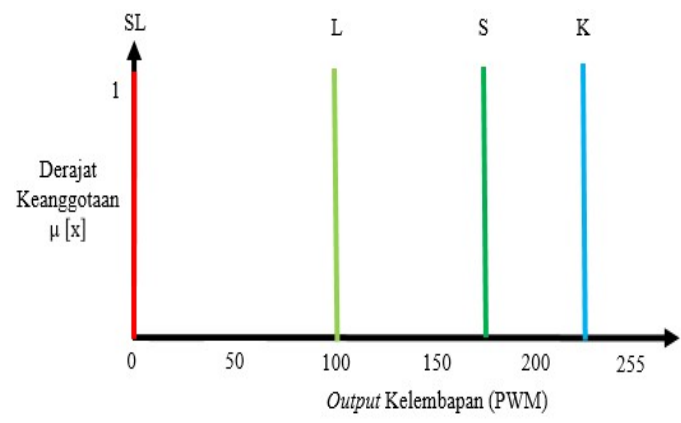

Gambar 7. Output Membership Function Kelembapan 
Berdasarkan hasil penelitian yang dilakukan sebelumnya, rules kelembapan yang akan dibuat adalah seperti pada tabel 3 .

Tabel 3. Rules Base Kendali Logika Fuzzy Kelembapan

\begin{tabular}{cccc}
\hline Eerror & EK & ES & EB \\
\hline DK & SL & $\mathrm{K}$ & $\mathrm{K}$ \\
$\mathrm{DS}$ & $\mathrm{SL}$ & $\mathrm{S}$ & $\mathrm{K}$ \\
$\mathrm{DB}$ & $\mathrm{SL}$ & $\mathrm{SL}$ & $\mathrm{K}$ \\
\hline
\end{tabular}

\subsection{Use Case Diagram pada Perancangan Website}

Use case diagram merupakan gambaran user dari sistem yang akan di bangun. Perancangan ini menjelaskan monitoring sistem pada website bagaimana arduino dan ESP8266 bekerja pada sistem yang bertugas mengambil data dari sensor dan mengendalikan output-nya sesuai dengan setpoin, kemudian mengirimkannya ke database. Berikut perancangan use case diagram perancangan website yang dapat dilihat pada gambar 8 .

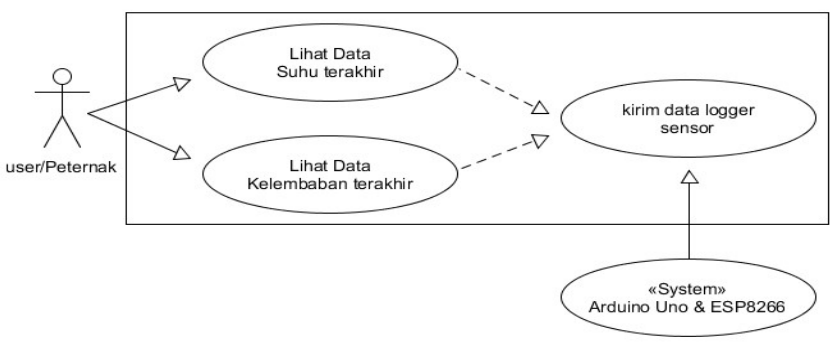

Gambar 8. Use Case Diagram Sistem Monitoring

\subsection{Pembuatan Mockup}

Pengembangan sistem monitoring pada website dengan menggunakan IoT, akan dirancang sebagaimana website yang akan dibangun. Tampilan mockup yang akan dirancang adalah sebagai berikut:

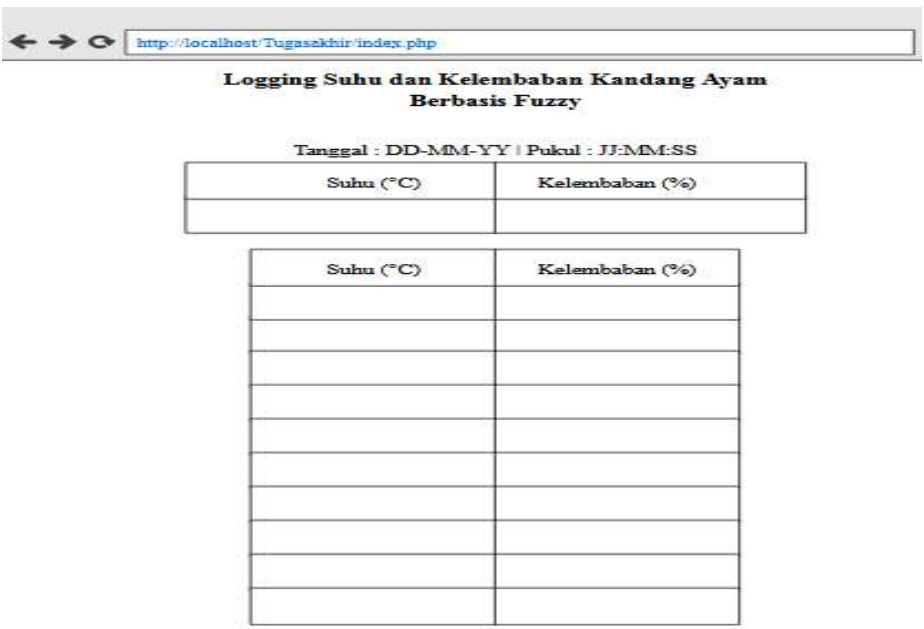

Gambar 9. Tampilan Website data Logging

Terdapat nilai suhu dan kelembapan yang terbaca dari sensor dan ringkasan data berupa waktu nilai terbaru suhu dan kelembapan yang telah terkirim ke website. kemudian terdapat tabel historis dari 10 nilai terakhir suhu dan kelembapan dari data yang terkirim sebelumnya ke website. 


\section{HASIL DAN PEMBAHASAN}

Pengaturan suhu dan kelembapan yang terdiri dari rangkaian power supply, LCD 16x2, socket Arduino Uno, sensor DS18B20, soket sensor DS18B20, sensor DHT22, modul AC dimmer, dan modul ESP8266. Pemanas dan pendingin berada di luar motherboard sistem.

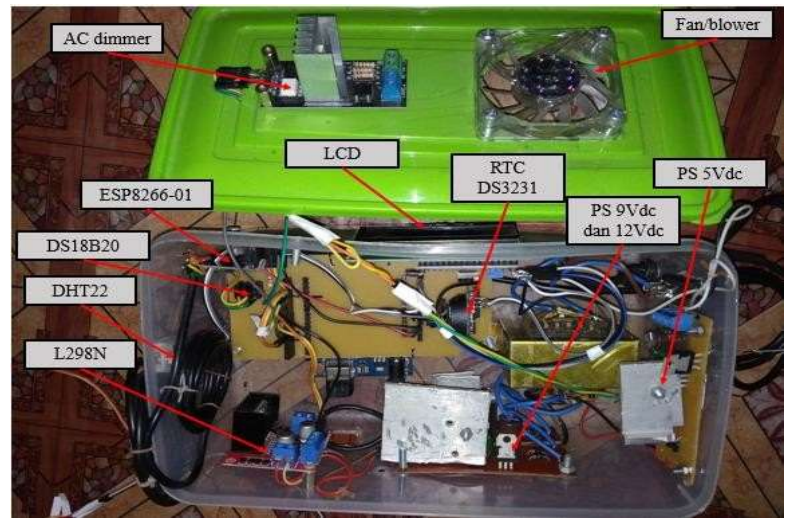

Gambar 10. Hasil Perancangan Alat Pengaturan Suhu dan Kelembapan

\subsection{Hasil Pengujian Kendali Fuzzy pada Kondisi Tanpa DOC}

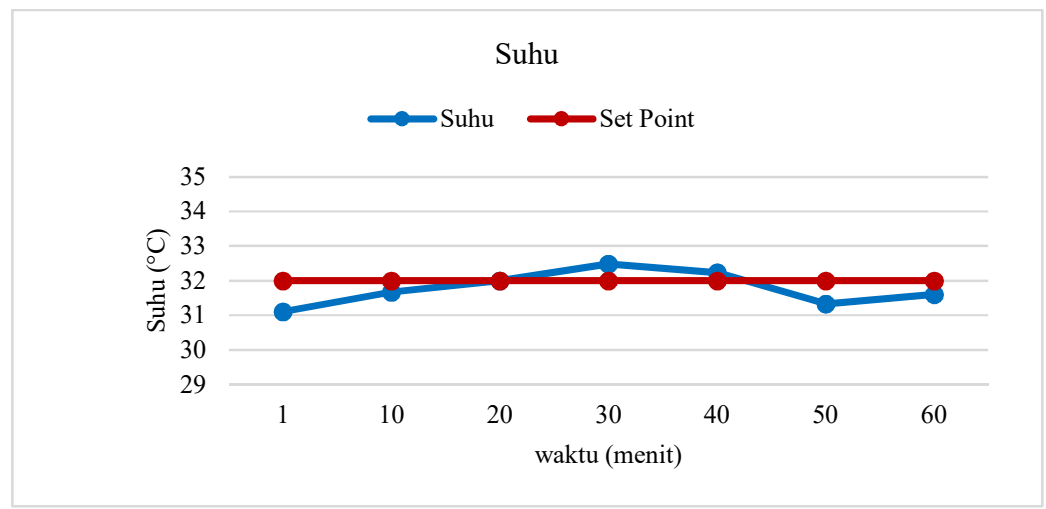

Gambar 10. Hasil Pengujian Suhu Tanpa DOC

Pengujian kendali fuzzy pada kondisi kandang tanpa DOC dilakukan pengambilan data setiap harinya, selama masa brooding. Pada pukul 08.00-09.00, 13.00-14.00, dan 20.00-21.00 selama 1 jam, setiap 10 menit sekali. Pengambilan waktu tersebut dilakukan karena perubahan suhu dan kelembapan yang tidak terlalu signifikan pada waktu pagi, siang dan malam hari. Berdasarkan hasil pengujian Gambar 10 yang dilakukan selama 1 jam dari pengujian selama masa brooding, dengan waktu 10 menit. Waktu yang di perlukan sistem untuk mencapai set point suhu adalah pada waktu 20 menit.

Hasil pengujian pada Gambar 11 menunjukkan sistem masih belum dapat mempertahankan nilai set point yang dibutuhkan. Berikut ini respon dari nilai suhu dan kelembapan pada grafik 1 dan grafik 2, menghasilkan parameter sebagai berikut:

1. Besarnya overshoot suhu adalah :

$$
\begin{aligned}
\text { Overshoot } & =32-32 \\
& =0
\end{aligned}
$$

2. Besarnya error steady state suhu adalah :

$$
\begin{aligned}
\text { Error steady state } & =32,48-32 \\
& =0,48
\end{aligned}
$$

3. Besarnya overshoot kelembapan adalah :

$$
\begin{aligned}
\text { Overshoot } & =65-65 \\
& =0
\end{aligned}
$$


4. Besarnya error steady state kelembapan adalah :

$$
\begin{aligned}
\text { Error steady state } & =65-65 \\
& =0
\end{aligned}
$$

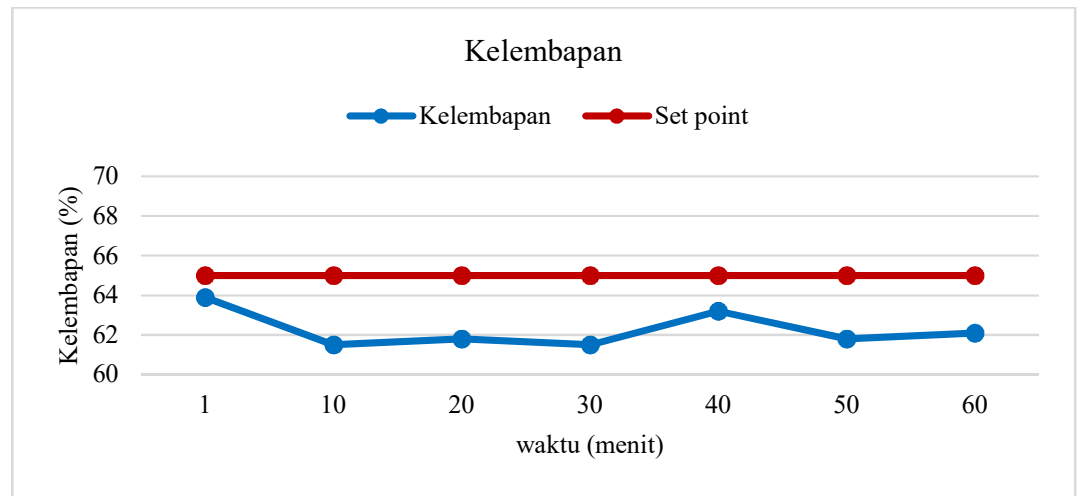

Gambar 11. Hasil Pengujian Kelembapan Tanpa DOC

\subsection{Hasil Pengujian Kendali Fuzzy pada Kondisi ada DOC}

Pengujian kendali fuzzy pada kondisi kandang ada DOC dilakukan pengambilan data selama masa brooding. pengambilan data juga dilakukan setiap harinya pada pukul 08.00-09.00, 13.00-14.00, dan 20.0021.00 selama 1 jam, setiap 10 menit sekali.

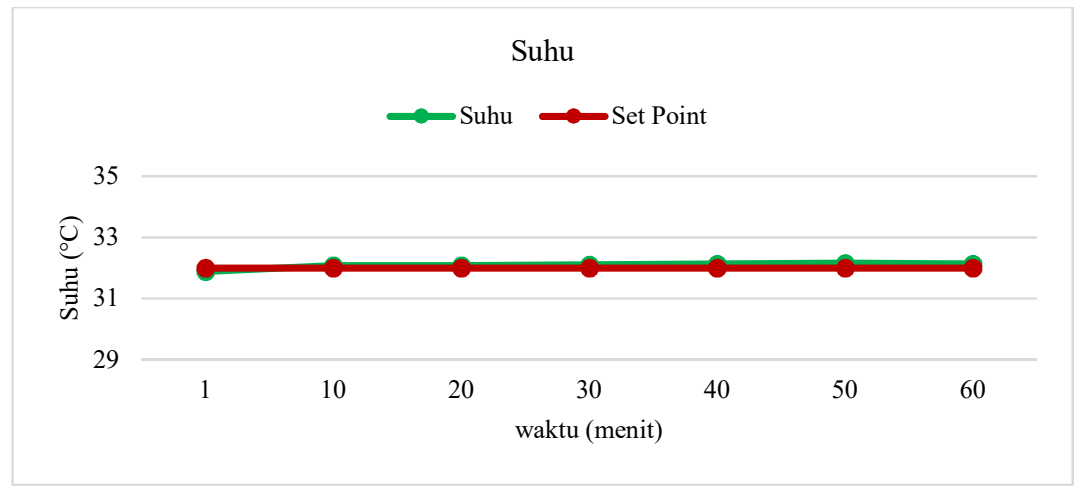

Gambar 12. Hasil Pengujian Suhu Ada DOC

Berdasarkan hasil pengujian grafik 3 yang dilakukan selama 1 jam, dengan waktu 10 menit. Waktu yang di perlukan sistem untuk mencapai set point suhu.

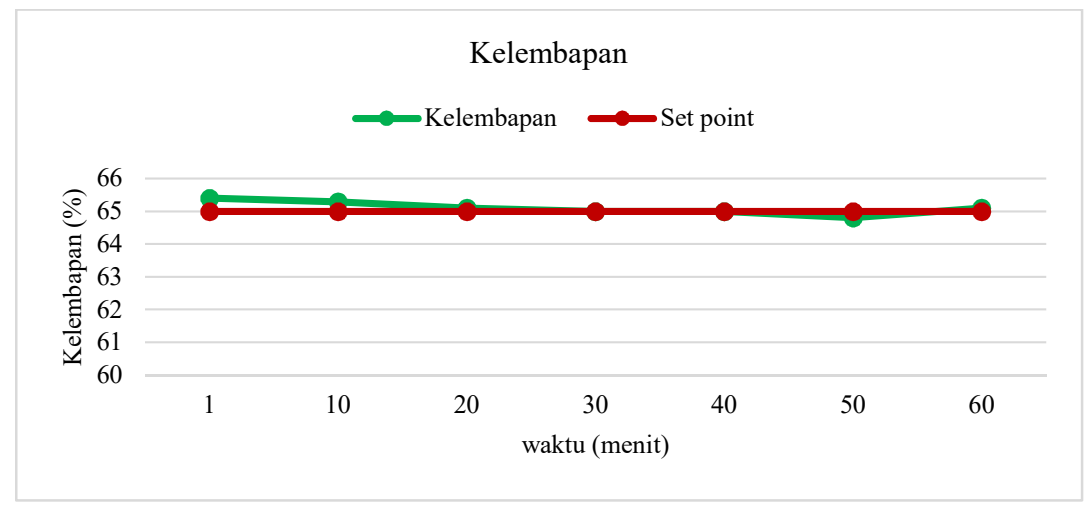

Gambar 13. Hasil Pengujian Kelembapan Ada DOC 
Pada grafik 4 hasil pengujian kelembapan, sistem telah dapat mempertahankan nilai set point yang dibutuhkan yaitu 65\%. Berikut ini respon dari nilai suhu dan kelembapan pada Gambar 12 dan Gambar 13, menghasilkan parameter sebagai berikut :

1. Besarnya overshoot suhu adalah :

$$
\begin{aligned}
\text { Overshoot } & =32,06-32 \\
& =0,06
\end{aligned}
$$

2. Besarnya error steady state suhu adalah :

$$
\begin{aligned}
\text { Error steady state } & =32,15-32 \\
& =0,15
\end{aligned}
$$

3. Besarnya overshoot kelembapan adalah :

$$
\begin{aligned}
\text { Overshoot } & =65,1-65 \\
& =0,1
\end{aligned}
$$

4. Besarnya error steady state kelembapan adalah :

$$
\begin{aligned}
\text { Error steady state } \quad & =65,4-65 \\
& =0,4
\end{aligned}
$$

\subsection{Hasil Implementasi Monitoring Website}

Hasil implementasi monitoring website dilakukan untuk mengetahui apakah sistem dapat dilakukan monitoring seperti konsep IoT. Berikut ini Gambar 14 hasil pengujian IoT pada masa brooding.

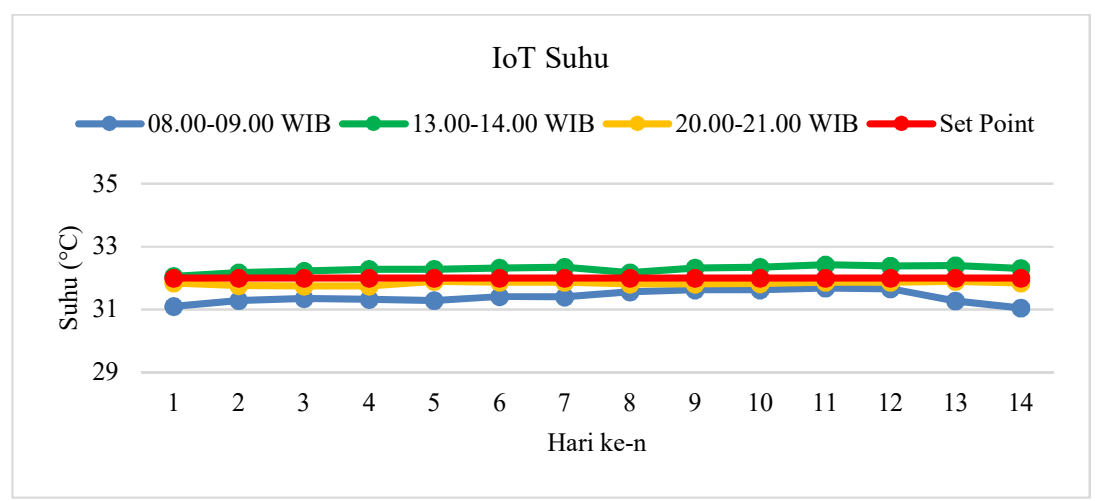

Gambar 14. IoT Suhu Sistem Keseluruhan

Berdasarkan hasil pengujian Gambar 14, nilai rata-rata suhu yang dibutuhkan pada set point dapat dilihat pada waktu pukul 13.00-14.00 WIB.

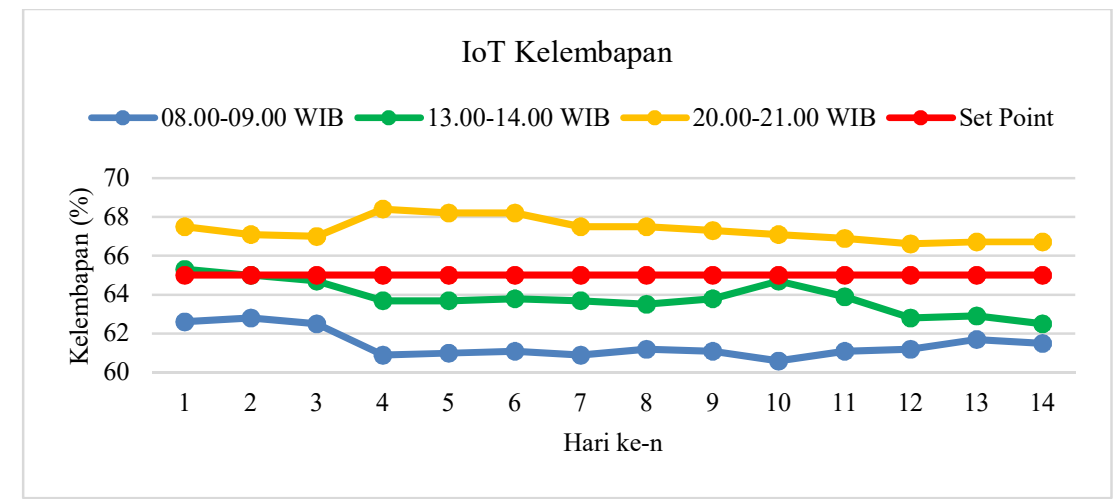

Gambar 15. IoT Kelembapan Sistem Keseluruhan 
Berdasarkan hasil pengujian Gambar 15, nilai rata-rata kelembapan yang dibutuhkan pada set point dapat dilihat pada waktu pukul 13.00-14.00 WIB. Kemudian monitoring dilakukan untuk mengetahui nilai suhu dan kelembapan terkini pada kandang yang terbaca oleh sensor.

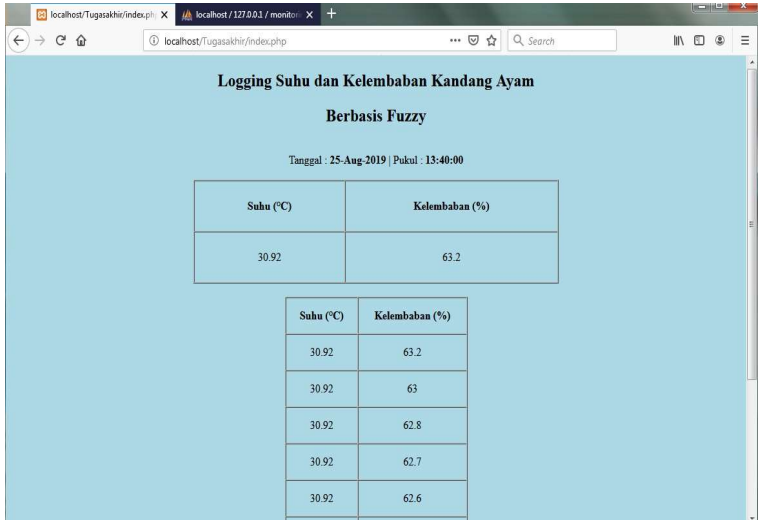

(a)

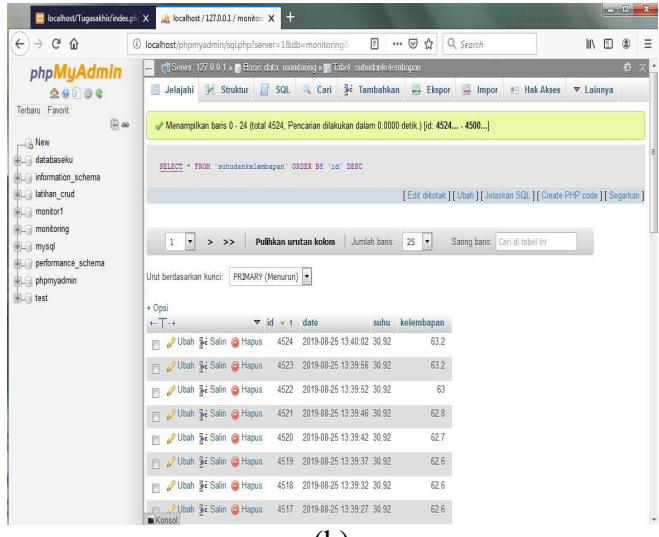

(b)

Gambar 16. (a) Tampilan Website Monitoring, (b) Tampilan Database Website Monitoring

Nilai suhu dan kelembapan yang terbaca oleh sistem pada gambar 11 dapat ditampilkan pada website. nilai suhu dan kelembapan terkini dapat diketahui, begitu juga dengan data historis 10 nilai terakhir dari data yang diterkirim oleh sistem. Nilai suhu dan kelembapan dapat terkirim ke database. Pada database tersebut dapat dilihat bahwa nilai suhu dan kelembapan yang terkirim adalah dalam waktu 5 detik sekali.

\subsection{Pertambahan Bobot Badan}

Pertambahan bobot badan (PBB) pada broiler dilakukan setelah broiler berumur 14 hari. Penimbangan dilakukan dari hari pertama DOC datang kemudian setiap minggunya, yaitu hari ke-7 dan hari ke-14. Nilai rata-rata PBB per harinya di dapatkan dengan membagi jumlah hari dengan pertambahan PBB yang terukur pada broiler.

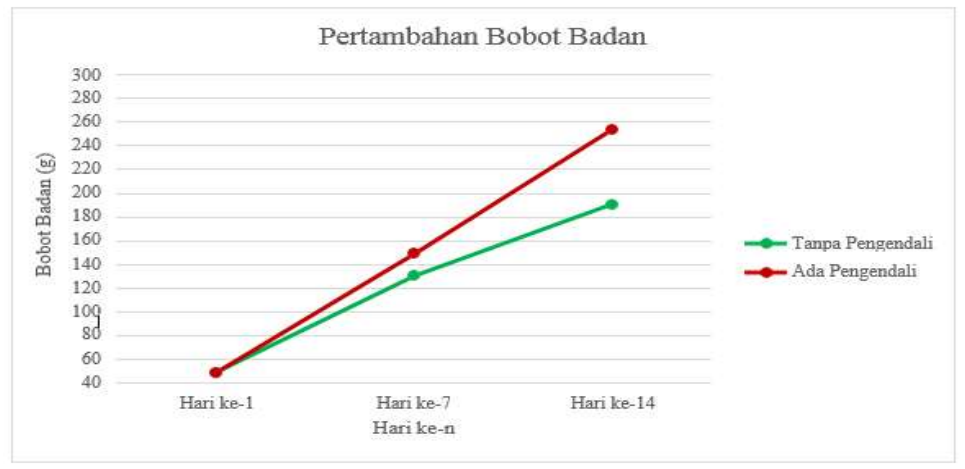

Gambar 17. Pertambahan Bobot Badan Rata-Rata

Pada Grafik 7 dapat dilihat bahwa pertumbuhan yang tidak seragam pada kondisi kandang tanpa pengendali dan ada pengendali dapat dilihat bahwa, kandang dengan pengendali menghasilkan PBB yang lebih baik dari $\mathrm{PBB}$ dengan kondisi kandang tanpa pengendali. Selain karena besarnya pengaruh iklim lingkungan sekitar sehingga pertumbuhan broiler menjadi kurang optimal. Pada penelitian ini, pengendalian yang dilakukan pada broiler umur 1-14 hari telah dapat mencapai pertumbuhan yang seragam, namun pada penelitian tanpa pengendali, pertumbuhan broiler masih belum dapat menghasilkan pertumbuhan yang seragam.

\section{KESIMPULAN}

Berdasarkan hasil pengujian bahwa pengendalian alat sistem monitoring pada pengaturan suhu dan kelembapan kandang ayam, telah mampu mencapai nilai set point dari suhu dan set point kelembapan dengan menggunakan kendali fuzzy. Sedangkan konsep IoT telah dapat di implementasikan dengan menampilkan 
nilai suhu dan kelembapan pada alat pengaturan suhu dan kelembapan, sehingga nilai suhu dan kelembapan kandang dapat dilakukan monitoring. Untuk hasil akhir yang didapatkan dari penelitian ini, adalah PBB pada broiler sampai pada masa brooding menghasilkan pertumbuhan yang seragam bila dibandingkan dengan pengaturan tanpa kendali terhadap suhu dan kelembapan yang dibutuhkan.

\section{REFERENSI}

[1] R. Fatmaningsiha, Riyanti, and K. Nova, "Performa Ayam Pedaging Pada Sistem Brooding Konvensional dan Thermos," J. Ilm. Peternak. Terpadu, vol. 4, no. 3, pp. 222-229, 2016.

[2] N. Juliasari, E. D. Hartanto, and S. Mulyati, "Monitoring Suhu dan Kelembaban pada Mesin Pembentukan Embrio Telur Ayam Berbasis Mikrokontroler Arduino UNO,” J. TICOM, vol. 4, no. 3, pp. 109-113, 2016.

[3] S. I. Hazami, S. Hardienata, and M. I. Suriansyah, "Model Pengatur Suhu Dan Kelembaban Kandang Ayam Broiler Menggunakan Mikrokontroler ATMega328 Dan Sensor DHT11," Jurusan Ilmu Komputer FMIPA, Universitas Pakuan. 2016.

[4] A. Ullah, O. B. Kharisma, and I. Santoso, "Fuzzy Logic Implementation to Control Temperature and Humidity in a Bread Proofing Machine," Indones. J. Artif. Intell. Data Min., vol. 1, no. 2, p. 66, 2018.

[5] M. Hidayat, "Pemanfaatan Tepung Duckweed (Lemna minor) dalam Ransum Terhadap Performa Ayam Ras Pedaging," Jurusan Peternakan, Universitas Islam Negeri Sultan Syarif Kasim Riau, 2019.

[6] Makmur, "Perancangan Prototipe Kandang Ayam Broiler Closed House Untuk Kontrol Suhu dan Kelembaban Berbasis Arduino Mega 2560," Jurusan Teknik Elektro, Universitas Muhammadiyah Surakarta. 2018.

[7] A. B. Laksono, "Rancang Bangun Sistem Pemberi Pakan Ayam Serta Monitoring Suhu dan Kelembaban Kandang Berbasis Atmega328," JE-Unisla Progr. Stud. Elektro, vol. 2, no. 2, 2017.

[8] A. A. Pratama, A. Rusdinar, and B. Setiadi, "Perancangan dan Realisasi Prototype Sistem Kontrol Otomatis Untuk Kandang Anak Ayam Menggunakan Metode Logika Fuzzy (Pemberi Pakan, Conveyor Berjalan, Kendali Suhu dan Kelembaban),” pp. 1-9, 2015.

\section{BIBLIOGRAFI PENULIS}

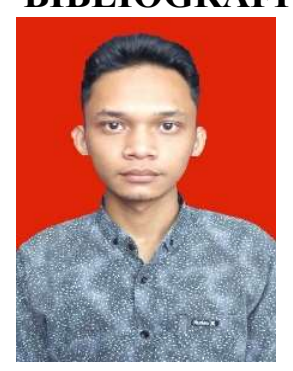

Jamaluddin Husein, ST yang akrab dipanggil jamal lahir di Desa Jambur Padang Matinggi Kab. Mandailing Natal pada 04 Maret 1996. Penulis merupakan anak pertama dari pasangan suami istri Bpk. Bahori Nasution dan Ibu Rabiah Nur Lubis yang beralamat di Desa Jambur Padang Matinggi Kec. Panyabungan Utara Kab. Mandailing Natal, Sumatera Utara. Kuliah di program studi Teknik Elektro UIN Suska Riau masuk pada tahun 2014 dan menyelesaikan kuliah tahun 2019.

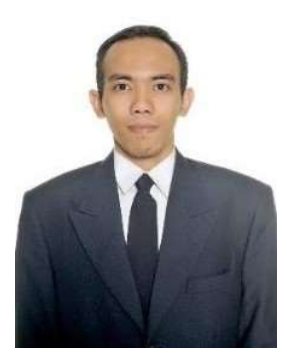

Oktaf Brillian Kharisma ST., MT., yang akrab dipanggil Oktaf. Lulus dari Teknik Elektro Universitas Jember tahun 2008. Tahun 2011 penulis melanjutkan Studi S2 di Computer Engineering Institut Teknologi Bandung. Saat ini penulis adalah Dosen di program Studi Teknik Elektro Fakultas Sains dan Teknologi UIN Sultan Syarif Kasim Riau. Bidang keahlian yang ditekuni adalah Robotika dan Sistem embedded. 